\title{
The Staffordshire (Ogley Hay) hoard: problems of interpretation
}

\author{
Leslie Webster, ${ }^{1}$ Christopher Sparey-Green, ${ }^{2}$ Patrick Périn ${ }^{3}$ \\ \& Catherine Hills ${ }^{4}$
}

\section{Implications of the artefacts}

\section{Leslie Webster}

The hoard presents us with a startling number of unfamiliar images from the Anglo-Saxon past, not least in the new icon of treasure that it presents. As the descriptions of treasure and gift-giving in Beowulf so vividly remind us, the gaining of treasure, and its corollary, gift-giving, were major preoccupations for Anglo-Saxons and their northern European contemporaries, whether Clovis, showering the crowds in Tours with gold solidi when he was created consul in 508, Oswiu attempting to buy off Penda before the Battle of Winwæd with what Bede (HE III.24; Colgrave \& Mynors 1969: 288-91) described as 'an incalculable and incredible store of royal treasures', or the huge Danegelds extorted by Vikings in the tenth and early eleventh century. But until July 2009, the picture presented by the archaeological evidence for Anglo-Saxon treasure could hardly have been more different: the material remains of treasure with which we are familiar come overwhelmingly from high-status burials, or as individual gold finds without context, most of them the result of relatively recent metal-detecting activity. Only one seventh-century Anglo-Saxon gold hoard exists, from Crondall in Hampshire, dated to $c$. 640; but that is essentially a coin hoard, the only non-numismatic items two small clasps which must have fastened the purse or satchel containing the coins. We have developed a set of tools for understanding the dynamics of burials and their contents, and to some extent, for the elegiac ideas and rituals which supported them; but because of their rarity, we lack specific experience in interpreting hoards, and the actions that shaped them.

The Staffordshire (Ogley Hay) hoard also challenges our notions about hoards in general, because it is quite unlike other hoards that we are familiar with - the big late Roman treasure-chests of jewellery, plate and coin, Middle Saxon coin hoards such as Woodham Walter or Crondall, coinless jewellers' hoards like that from Pentney, and mixed Vikingperiod hoards such as those from Trewhiddle or bullion-rich Cuerdale. This very male treasure, with its systematically dismembered war-gear, its crumpled Christian talismans,

1 Former Keeper, Department of Prehistory and Europe, The British Museum, Great Russell Street, London WC1B 3DG, UK (Email: arachne55@tiscali.co.uk)

2 (Email: christopher.sparey-green@mypostoffice.co.uk)

3 Directeur du musée d'Archéologie nationale et Domaine national de Saint-Germain-en-Laye, 2 Rue Thiers, 78100 Saint-Germain-en-Laye, France (Email:patrick.perin@culture.gouv.fr)

4 Department of Archaeology, University of Cambridge, Downing Street, Cambridge CB2 3DZ, UK (Email: ch35@cam.ac.uk) 
and its total lack of coins, is a hoard of a quite exceptional kind; not even the earlier great Scandinavian weapon deposits, with their full array of intact weapons, are really comparable. We will need to work out fresh approaches to address the nature and meaning of this extraordinary construct, and the questions to be asked are many.

First among these are two very separate questions, why was it assembled? And why was it buried? These will continue to be vigorously debated; but some preliminary observations can be made. The rough stripping, and in many cases, reduction to small fragments, of the swords and other artefacts is striking, and has led to suggestions that this is battle booty of some kind, even a ritual deposit. But it is also a curiously non-random selection. Hilt fittings from swords and seaxes abound, along with a few pyramidal sword mounts, but there are none of the other essential sword fittings that one would expect - scabbard mounts, or buckles and other fittings from sword belts, and most conspicuously of all, there are no iron blades from weapons. Only one possible shield fitting is present, and with the exception of a few helmet fragments, body armour is absent; yet prominent among the finest metalwork in the hoard are many distinctive decorated cloisonné fittings from different matching suites of as yet unknown purpose. Some may conceivably come from saddles, or even other horse accoutrements, but none of the usual horse gear, as seen for instance in Sutton Hoo Mound 17, is represented here (Carver 2005: 221-41). These are riddles waiting to be unpicked. Along with the Christian talismans - the compressed processional cross, at least one pendant cross and the inscribed fragment, with its fierce text invoking God to scatter the enemy - which possibly comes from another cross - these may suggest a more ceremonial element in the assemblage. But it is the absent elements as much as the present ones that invite questions about the hoard's assemblage, and its deposition. The iron sword and seax blades might conceivably have been removed for re-use, but the absence of other sword fittings, and helmet parts, not to mention other key elements of warrior kit such as shields and spears, strongly suggests that we do not have the whole story here. Excavation and survey to date has suggested that the assemblage as retrieved is complete, and that there is no evidence for other deposits elsewhere in the field.

What might this mean? Many well-furnished seventh-century Anglo-Saxon male burials - Taplow, Broomfield and Prittlewell among them - contain swords that lack their pommel-caps (Hirst 2004: 29; Webster 2007). Were such fittings removed before burial, perhaps for re-use on a newer blade, and could that be what we see in the hoard - objects intended for re-use? The severely damaged condition of many of the Staffordshire hilt mounts, and the extensively fragmented condition of other objects in the hoard, suggest that such was not the case here. One might understand the absence of ironwork in terms of the hoard being essentially an assemblage which was probably destined for the melting pot, and that might indeed have been its fate; but that alone does not explain the conspicuous absence of the complementary warrior accoutrements that might have been expected, or the presence of incomplete objects, such as the helmet(s). This suggests that the hoard as we have it is only part of the original assemblage, some of which perhaps never entered the ground. In this reading, it is essentially precious scrap put together for recycling, and might have formed part of a consignment of disassembled military equipment (whether as a result of battle, as the accompanying protective crosses might suggest, or of some other, unknown, process), which was somehow diverted from its destination. Della Hooke 
(above) has shown how its findspot, close by the main thoroughfare of Watling Street, lay in marginal scrubland, notorious for robbers as late as the seventeenth century, raising the enticing possibility that the hoard was buried there as part of the proceeds of ambush and robbery of an escort travelling along the road, rather than as a parcel of some special kind of offering.

Assigning a date to the hoard is equally challenging. First of all, there is the curious fact that most of the silver sword pommels can be dated to the mid sixth century, some of them perhaps even earlier, though others seem to belong to the later seventh century, while the majority of the gold cloisonné sword and seax fittings (indeed most of the cloisonné material) appear to belong to what we conventionally think of as the Sutton Hoo horizon of the first third of the seventh century. The distinctively loose filigree on some pommels may indicate a later date, or may simply reflect a different workshop tradition — another factor that needs to be borne in mind when trying to date such a varied and idiosyncratic assemblage. Many of these gold pommels also show significant wear, suggesting that they were buried perhaps 40 years after manufacture. One hundred and fifty years is a remarkably long span for such an assemblage, even allowing for the fact that we know from later wills and poetry that swords could be treasured as heirlooms, and raises questions about the nature of the hoard - again perhaps favouring some sort of recycling explanation, rather than the direct result of a battle. Add to this the stylistic and epigraphic conundrums that arise when we apply conventional art-historical and palaeographical dating to some of the objects, and we also begin to see that the dating of the hoard poses fundamental questions about the chronology of material culture in this period.

The coin-associated garnet-inlaid objects in the Sutton Hoo Mound 1 burial have generally been assumed to have been buried around the third decade of the seventh century, implying a slightly earlier manufacturing date, as they mostly show little wear. Many of the gold and garnet cloisonné objects in the Staffordshire hoard seem close in style to the Sutton Hoo garnet work, though, as noted above, the marked wear exhibited by the gold pommels indicates that their deposit could have been as much as 40 or more years later. It remains a fact, however, that our knowledge of the chronology of swords and their fittings from the second half of the seventh century is uncertain, since they became increasingly rare in burials, as mortuary practices underwent increasing change; perhaps such sword pommel types continued later than we currently think. Parallels from the earliest Insular manuscripts add to the uncertainty. The Book of Durrow contains Style 2 zoomorphic decoration closely related to that on the Sutton Hoo shoulder clasps, and for that reason, was for a while assigned to the first half of the seventh century, though textual comparisons suggest a date later in the seventh or even early eighth century; a date of c. 670-680 currently prevails. But this decoration is also very closely related to that on the folded processional cross in the hoard, which looks crisp and freshly made. A date of $c .680$ for the cross is attractive, and could sit well with the implied deposition date implied by the well-worn gold sword pommels.

However, an even more striking parallel to the Durrowesque animals on the cross can be seen on the rim mounts of the Sutton Hoo maplewood bottles, showing that the two shared a closely similar, possibly identical, model. The implications, not only for the Staffordshire cross, but for the dating of Durrow, and other early decorated Insular manuscripts, are 
dramatic. The chronology of manuscripts and metalwork in the seventh century is clearly one of the main areas where the hoard is going to change our mental map of the period. Key in this is an assessment of what stylistic differences - and similarities - may mean; to what extent are the wide stylistic variations evident in the hoard a matter of regional or workshop distinctions (e.g. so-called 'Anglian' Style 2 beasts, vs 'Kentish' equivalents), rather than representative of different dates of manufacture, or even different techniques? Analysis of the wide range of decoration on objects in the hoard, alongside analysis of the gold content, may help to build a more secure understanding of stylistic development and variation during the seventh century, as well as sharpening our understanding of workshop organisation and production.

The date of the cross fragment with the biblical inscription is one important piece which has yet to fit comfortably into the jigsaw. It has distinctive zoomorphic decoration of an animal head and tiny snakes, which find their best parallels in seventh-century manuscripts and metalwork; as for the inscription itself, the verdicts of palaeographers and epigraphers suggest that it floats somewhere between the early years of the Augustinian mission (from AD 597) and the eighth century, where some epigraphic parallels survive - another indication of the partial nature and uncertainty of our present state of knowledge. This fragment, with its scriptural text which both reinforces the power of the cross, and places it in the specific context of warfare, is also linked in apotropaic function to the hoard's more complete processional cross, which has zoomorphic decoration derived from a pre-Christian iconography connecting this world to another, conferring power and protection. Both open up in this martial context a new perspective on the indivisibility of the secular and the sacred in this period.

One factor that has inevitably attracted much attention is the remarkable quantity of gold and silver in the hoard, unparalleled among Anglo-Saxon archaeological finds. It shows for the first time that significant wealth was circulating in a part of the country about which we have little documentation and less archaeology, and in just the period in which the kingdom of Mercia was beginning to extend and exert its power. But as John Hines and others have cautioned, this is not, by the evidence of the seventh-century Kentish laws of Hlothere and Eadric, an exceptional amount - the equivalent of around the wergilds of 12-14 noblemen, rated at 300 shillings each — hardly enough for a king's retinue, let alone an army (Hines 2010: 169). Nevertheless, the wealth and quantity of items in the hoard point to new avenues of research; on social organisation and ranking, on the nature and control of treasure, and its social and economic role in a period of considerable change and turmoil. We are used to the notion that Byzantine and Merovingian gold coins, and older jewellery, were the raw material from which high-end metalwork were manufactured; but the mere fact that this hoard has no surviving parallel is a vivid demonstration of just how important and effective the management of precious metals was in Anglo-Saxon England.

To return finally to the question of the date of the hoard, and its wider context: despite the fragility of chronologies and the patchiness of comparabilia, current opinion is that the hoard was probably buried around the end of the seventh century. Of course, the apparent presence of objects of Northumbrian, East Anglian and Kentish origin in the hoard temptingly fit what little we know of the campaigns of aggressive Mercian kings in the second half of the seventh century and the earlier eighth century. It is also striking, but almost certainly 


\section{Leslie Webster et al.}

coincidental, that the earliest other Anglo-Saxon appearances of the biblical quotation that appears on the inscribed fragment are in the eighth-century prose life of the Mercian warrior saint, Guthlac, who, according to his biographer, invoked it twice — first to dispel the devils that tormented him in his Fenland hermitage, and again when he sought to console the exiled Æthelbald that he would (as indeed he did) attain the Mercian throne (Life of St Guthlac ch. 34, 49; Colgrave 1956: 108-111, 150-151). But precise identification with events or personages is to be resisted; what we know about seventh-century England from Bede and a few other equally partial sources, is far outweighed by what we don't know. The Staffordshire hoard certainly reflects in some way the wealth and power of Mercia in its ascendancy — but to define its context beyond that seems at present, and probably forever, a step too far. Perhaps indeed the most important thing the hoard has reminded us of is just how very little we know, not only about the historical events of the seventh and early eighth centuries, but about the social frameworks and mentalities that shaped them, the wealth that fuelled them and the power bases that underpinned them. All the same, though we may never know its true story, this extraordinary assemblage will change forever the map by which we navigate the often obscure and difficult terrain of middle Saxon England.

\section{A royal hall?}

\section{Christopher Sparey-Green}

One thing is certain about the latest bullion from the English countryside, it is an unusual hoard and contains some unique objects. Another Sutton Hoo it is not, and it is hardly the archaeological equivalent of the Book of Kells. But how so much rich metalwork could come to be scattered in the topsoil of a recently cultivated pasture is unexplained, since no primary context or burial pit has apparently been identified.

The weight of gold bullion $(c .5 .1 \mathrm{~kg})$ as compared with Sutton Hoo $(1.660 \mathrm{~kg})$ is not exactly an important factor in the archaeological interpretation of the site but the quantity of items, mostly fittings from Anglo-Saxon swords but including some magnificent bent crosses and jewelled fittings, will be the cause of much speculation. The presence of something like 650 scraps and 56 earth lumps containing tiny fragments of metal suggests detritus from an early goldsmith - a precursor of more recent metalworkers in the Birmingham area. This writer wonders if it is the product of Viking raids on some royal hall decked with museum pieces from past battles, the rusty and antiquated blades discarded, the gold and silver fittings in the process of reworking.

\section{A pagan sanctuary?}

\section{Patrick Périn}

The hoard is notable for the predominance of objects of military character, but absence of iron blades, spears, axes and shields. There are no pieces that have a feminine or feasting association. It must therefore have been deliberately selected. The oldest artefacts date to the second half of the sixth century, the youngest to the late seventh or early eighth century. The state of preservation is poor: nearly all the objects are fragmented and twisted. Were 
they deliberately broken up before burial or pulled apart by later ploughing? The possible circumstances for burial that we might envisage at the end of the seventh or beginning of the eighth century would include a threat of invasion, the concealment of stolen goods or a ritual deposit.

These can perhaps be combined into an integrated narrative. The incremental character of the hoard, where objects of different dates are added over a century or more, excludes the idea of the booty from a battlefield. Likewise, if the collection belonged to a royal or ecclesiastical treasury, it should have contained other kinds of objects than swords, helmets and crosses. The best option, as it appears to me, is that the collection was amassed as ritual deposition in a pagan sanctuary. This place was subsequently raided, and the collection acquired by a goldsmith, who extracted the precious metal and gems before the remains were buried in unknown circumstances.

\section{The primacy of context}

\section{Catherine Hills}

The news of the discovery of the Staffordshire hoard prompted the thought that it might be the first example in England of a type of site known from the first millennium $\mathrm{AD}$ in southern Scandinavia. Best known of these are Nydam and Illerup, in Jutland, where weapons, interpreted as belonging to defeated enemies, were thrown into lakes, mostly between $c$. AD 200 and AD 500. Some of these deposits include thousands of items: spears, shields, swords, belts and horse-trappings, amounting to the entire equipment of armies which must have numbered in hundreds if not over a thousand (Jorgensen et al. 2003). One deposit at Nydam, dated to the late fifth century, included 36 swords, some with gilded pommels, all drawn from their scabbards and deliberately broken before being driven into the mud at the edge of the lake. The Staffordshire hoard is later in date, it had sword fittings without blades and it was found in a very different topographical setting from the Scandinavian lakes: but the concept of the sacrifice of weapons or part of them is comparable.

In the same period in Scandinavia, many gold objects, including sword fittings and ornaments, have been found in or near house foundations. Some of the objects are very small, thin foil figural plaques (guldgubbe). Those examples buried in postholes, at least, were clearly not buried for safe keeping and future retrieval.

A third kind of deposit has been recognised recently at Uppåkra, near Lund in southern Scandinavia (Helgesson 2004; Herschend 2010: 369-77). Here weapons were strewn over the ground near to a building of an unusual kind. It was not very large but had massive posts, and it had been rebuilt to the same plan and on the same site for centuries, from the Early Roman period possibly to the start of the Viking period. There was then a period of destruction, in the course of which buildings and people were burnt. The weapons were of different dates, but of a similar state of preservation. Two scenarios were suggested: either weapons were deposited over a long period of time outside the buildings, or a collection of weapons had been assembled over a long period, the collection then seized, the weapons broken and thrown over the ground in the course of the destruction of the buildings following the defeat of its rulers. An illustration of the excavation supports the latter interpretation 
(Helgesson 2004: fig. 3). One of the finds was the brow ridge of a helmet comparable to the Sutton Hoo, Vendel and Valsgärde helmets of late sixth-/early seventh-century date. This is an ongoing project and so not yet fully published but it is clear that it includes the deposition on dry land of deliberately broken weapons at a date that might be contemporary with the manufacture of some of the items in the Staffordshire hoard. It also suggests that weapons could be assembled over a long period into collections that might be practical armouries or cult assemblages.

Another important point is that weapon burial was in decline in Denmark at the time of the deposits; indeed there are hardly any known from the fifth century. Estimates of population, let alone the size of armies, based on burial evidence would be very much smaller than we can deduce from the lake offerings. It is possible that we have similarly underestimated the scale of weaponry in Anglo-Saxon England: most cemeteries have 0-3 swords, not 92 .

Elements of all the above might be relevant in interpreting the Staffordshire hoard, but unfortunately the circumstances of its discovery mean that we shall probably never know. I have read the accounts of the discovery and fieldwork in the media, in this journal, and in The Antiquaries Journal (Dean et al. 2010) and I attended the British Museum symposium in March 2010. From all of these it appears to me that not only the detectorist, but also the team from Birmingham Archaeology, had as their primary concern the recovery of precious metal, i.e. they were treasure hunting. This is entirely understandable for Mr Herbert, who was indeed looking for treasure, but not for professional archaeologists. The purpose of archaeology is the recovery of information about past human behaviour, not treasure. What was needed was careful recording in situ of what was left of the hoard, and its expert excavation and recovery for conservation, followed by a carefully planned investigation of the rest of the field with the aim of finding out more about what activities had happened there at any date before July 2009.

This was not a simple task, and it required specialist skills and consultation with relevant experts. It would have been easy to contact experts known to those involved: John Hunter, Professor of Archaeology at Birmingham University, where Birmingham Archaeology is based, is a specialist in early medieval archaeology and forensic archaeology, with long experience of working with the police - which might have been doubly appropriate; staff of the conservation department of the British Museum, where the Portable Antiquities Scheme is based, have had years of experience of excavating fragile and valuable artefacts; the editor of this journal, Martin Carver, is the founder of BUFAU, predecessor of Birmingham Archaeology, and excavated at Sutton Hoo, the site which has produced finds most comparable to those of the hoard. I remain puzzled and frustrated that none of these people were consulted before the find was made public. The genuine need for secrecy and security, to protect the site from looting, was extended to absurdity by excluding proper consultation. Even the later period of fieldwork in March 2010 was carried out without wider consultation.

There may have been some misapprehension that excavation is a simple and straightforward activity, combined with a belief that it is not possible to recover contextual information from plough soil. Cutting out and sieving were thus seen as an appropriate means of retrieving finds, though the fragility of the objects must soon have contradicted 
that. But a first ploughing, as this might have been, would have retained distribution patterns from which it might have been possible to confirm that this was indeed one deposit, and not several, and exactly where, and how deep, it had been buried, in what kind of container(s) and possibly further information on relative sequences of events in that field.

It is true the conditions were bad: digging a clay site in the wettest July on record, sworn to secrecy, must have been difficult and stressful for those digging, who were working hard to clear the site as quickly as possible. But it seems as if the priorities of metal-detecting took over from those of archaeological investigation, so that the methods used did not maximise archaeological information and led to damage to finds. In Steven Dean's lecture at the British Museum symposium he showed a picture of one object with the comment that it had been damaged 'by plough or trowel — who knows?'There were incredulous messages from archaeologists in the USA on seeing the video clip of a trowel slicing vertically through clay (and probably through gold fragments). The lumps carefully retrieved by Herbert, which may well have been bags, were X-rayed, but then the soil (?leather) was washed off, along with all the information it might have contained. The number of objects reported should have been smaller: many are fragments which were broken not just by the plough, and not it seems primarily by Mr Herbert - but in the course of the excavation.

Overall, the impression given by the press coverage was that archaeology is also treasure hunting: the recognition that what distinguishes archaeology is the painstaking recording and interpretation of the relationships observed in the ground seems to have disappeared. The British Museum symposium perpetuated the media perception. Many excellent and interesting lectures were given on all aspects of the material - art-historical and historical contexts, the inscription, technical analyses, comparative material; but none of this provides a reliable foundation for interpreting the deposition of the hoard itself, from which all the other studies should start.

It is true that we may still learn much about the technology and stylistic development of Anglo-Saxon sword fittings, and probably much else, but that will not 'rewrite the Dark Ages'. Much of what we eventually learn will be through applying to this new material the knowledge already gained over many years through study of objects that have been excavated and recorded properly in situ. We lack the starting point of knowing what kind of deposit this was, and when it was put into a field near Watling Street in the parish of Ogley Hay. Was it an early medieval Scandinavian-style votive deposit of the hilts of destroyed enemy weapons? Viking loot from a monastic treasury? Or a bag of scrap metal abandoned by a thief, like the one who took and melted down the finds from Childeric's grave in 1831?

\section{References}

CARVER, M.O.H. 2005. Sutton Hoo, a seventh-century princely burial ground and its context (Reports of the Research Committee of the Society of Antiquaries of London 69). London: British Museum Press.

Colgrave, B. \& R.A.B. Mynors. 1969. Bede's Ecclesiastical History of the English people. Oxford: Oxford University Press.

Colgrave, B. 1956. Felix's Life of St Guthlac. Cambridge: Cambridge University Press.
DeAn, S., D. HoOke \& R.A. Jones. 2010. The 'Staffordshire hoard': the fieldwork. The Antiquaries Journal 90: 139-52.

Helgesson, B. 2004. Tributes to be spoken of: sacrifice and warriors at Uppåkra, in L. Larsson (ed.) Continuity for centuries: a ceremonial building and its context at Uppåkra, southern Sweden (Acta Archaeologica Lundensia 48): 223-39. Lund: Almqvist \& Wiksell. 


\section{Leslie Webster et al.}

Herschend, F. 2010. The early Iron Age in South Scandinavia: social order in settlement and landscape (Occasional Papers in Archaeology, Societas Archaeologica Upsaliensis 46). Uppsala: Uppsala Universitet.

HINES, J. 2010. Units of account in gold and silver in seventh century England. Antiquaries Journal 90: $153-73$.
HiRsT, S. 2004. The Prittlewell prince: the discovery of a rich Anglo-Saxon burial in Essex. London: Museum of London Archaeology Service.

Jørgensen, L., B. StorgaArd \& L. Gebauer

THOMSEN (ed.). 2003 The spoils of victory: the north in the shadow of the Roman Empire. Copenhagen: Nationalmuseet.

WebSTER, L. 2007. Taplow, in Reallexikon der Germanische Altertumskunde 35: 69-72. Berlin \& New York: Walter de Gruyter. 